\title{
Effects of transient and persistent cerebrospinal fluid drainage on sleep disordered breathing in patients with idiopathic adult hydrocephalus syndrome
}

\author{
Bo Kristensen, Jan Malm, Terje Rabben
}

\begin{abstract}
Objectives-To examine sleep disordered breathing including obstructive sleep apnoea in patients with idiopathic adult hydrocephalus syndrome (IAHS) and to study the effects of CSF drainage and shunting procedure on sleep disordered breathing.

Methods-In 17 patients with IAHS polysomnographic investigations were performed before and after lumbar CSF drainage and after shunt operation.

Results-Baseline investigations documented a high prevalence of sleep related obstructive respiratory events (respiratory disturbance index $>10$ in $65 \%$ of the patients) and impaired sleep structure. There was no correlation between respiratory disturbance index and CSF pressure. Minimum oxygen saturation was highly correlated with cognitive function. Neither lumbar CSF drainage nor shunting alleviated the respiratory disturbance index. REM and delta sleep increased initially after shunting but there was no sustained effect on sleep quality.

Conclusions-Sleep disordered breathing is a prevalent finding in patients with IAHS. The shortcoming of CSF drainage to improve sleep disordered breathing either transiently or permanently implies that sleep disordered breathing is a coexistent condition, or an irreversible consequence of the hydrocephalus, with a potential of causing additional dysfunction in IAHS.

(F Neurol Neurosurg Psychiatry 1998;65:497-501)
\end{abstract}

Department of Clinical

Neuroscience, Umea

University Hospital,

Sweden

B Kristensen

J Malm

T Rabben

Correspondence to:

Dr Bo Kristensen,

Department of Clinica

Neuroscience, University

Hospital, S-901 85 Umea,

Sweden. Telephone 004690

7852376; fax 004690

143107; email

Bo.Kristensen@neuro.umu.se

Received 18 November 1997 and in revised form

8 April 1998

Accepted 16 April 1998
Keywords: hydrocephalus; cerebrospinal fluid hydrodynamics; polysomnography; sleep disordered breathing

Sleep disordered breathing, including obstructive sleep apnoea, is a common condition. ${ }^{1}$ It is defined as the presence of apnoeas or hypopnoeas usually associated with a reduction in blood oxygen saturation and sleep fragmentation.

The medical literature suggests that adult hydrocephalus syndrome (AHS) and sleep disordered breathing may in some cases be associated disorders with important implications for diagnosis and treatment with a belief that shunt operations can reduce the number of apnoeas. $^{23}$
The aims of the present study were to investigate the prevalence of sleep disordered breathing and related abnormalities in sleep structure in idiopathic adult hydrocephalus syndrome (IAMS) and to evaluate if lumbar CSF drainage (CSF tap test) and shunting procedure had any effect on breathing pattern during sleep and sleep structure.

Patients and methods

A prospective study of IAHS has been carried out at the Department of Neurology, University Hospital of Umea since $1988 .^{4}$ For the purpose of this study 17 patients (12 men and five women, mean age 72.2 (SD 3.7) years) were included. The inclusion was dependent only on the acceptance on behalf of the patients and the access to the technical facilities.

The diagnosis was based on (1) a gait disturbance as a predominant and obligate symptom, (2) mental impairment or urinary incontinence, or both (ranging from not clinically present to severe disturbances), (3) CT with dilatation of the lateral ventricles but without severe cortical atrophy, and (4) absence of another disease which might explain the clinical symptoms or radiological findings. None of the patients had an obvious precipitating cause such as subarachnoid haemorrhage, meningitis, or neurosurgery. All patients were therefore considered to be of idiopathic type, although the symptoms appeared in one patient after a minor cranial trauma.

Clinical characteristics of the patients were assessed by a neurological evaluation and careful history obtained from both the patient and a relative. Routine laboratory tests were performed. ${ }^{5}$ Global cognitive status was assessed by means of the mini mental state examination (MMSE), ${ }^{6}$ activities of daily life by the Bartel index, ${ }^{7}$ and an ischaemic score was assigned. ${ }^{8}$ The evaluation of gait function has previously been described in detail. ${ }^{5}$ The same clinical variables and CSF hydrodynamic assessment of shunt function were evaluated 3 months after shunt surgery. Definitions of improvement has been detailed elsewhere. ${ }^{5}$ The width of the lateral ventricles on CT was measured as a ventricular index. ${ }^{9}$ The Hakim standard system was used in 11 patients and the Orbis Sigma ${ }^{\mathrm{TM}}$ valve in six patients. Informed consent for all aspects of the study was obtained. 
Table 1 Baseline characteristics of patients and clinical outcome after shunting in 17 patients with idiopathic adult hydrocephalus syndrome

\begin{tabular}{|c|c|}
\hline Characteristics & Mean (SD) \\
\hline Patients (n) & 17 \\
\hline Age $(y)$ & $72.2(3.7)$ \\
\hline $\operatorname{Sex}(F / M)$ & $5 / 12$ \\
\hline Body mass index & $25.4(3.0)$ \\
\hline Ischaemic score (points) ${ }^{7}$ & $2.2(1.9)$ \\
\hline Hypertension (medically treated) (\%) & 56 \\
\hline Diabetes (\%) & 26 \\
\hline Ischaemic heart disease (\%) & 22 \\
\hline \multicolumn{2}{|l|}{ Severity of disease: } \\
\hline Mini mental state estimation (points) ${ }^{5}$ & $23.7(5.6)$ \\
\hline Bartel (points; $\max 70$ points) ${ }^{6}$ & $66.2(18.6)$ \\
\hline Gait velocity $(\mathrm{m} / \mathrm{s})$ & $0.8(0.4)$ \\
\hline \multicolumn{2}{|l|}{ Symptoms: } \\
\hline Gait & 5 \\
\hline Gait + dementia & 4 \\
\hline Gait + incontinence & 5 \\
\hline Gait + dementia + incontinence & 3 \\
\hline \multicolumn{2}{|l|}{ Duration of disease $(\mathrm{y} \%)$ : } \\
\hline$<1$ & 28 \\
\hline $1-2$ & 39 \\
\hline$>3$ & 44 \\
\hline \multicolumn{2}{|l|}{ CSF hydrodynamics: } \\
\hline $\mathrm{Pcl}(\mathrm{kPa})$ & $2.0(0.6)$ \\
\hline Gop $\left(\mathrm{mm}^{3} / \mathrm{kPa} \times \mathrm{s}\right)$ & $9.4(3.6)$ \\
\hline \multicolumn{2}{|l|}{ CT scan: } \\
\hline Frontal horn index ${ }^{8}$ & $0.34(0.04)$ \\
\hline \multicolumn{2}{|l|}{ Outcome ( 3 months postoperative, gait, $\%$ ): } \\
\hline Marked improvement & 44 \\
\hline Moderate improvement & 34 \\
\hline No improvement & 22 \\
\hline
\end{tabular}

Pcl=lumbar CSF pressure; Gop=CSF outflow conductance.

CSF HYDRODYNAMICS

The CSF hydrodynamic studies were performed preoperatively and the constant pressure technique was used. ${ }^{10} \mathrm{CSF}$ pressure $(\mathrm{Pcl})$ and the conductance of the CSF outflow pathways (Gop) were determined. The normal values for CSF hydrodynamic variables have been published elsewhere. ${ }^{11}$

At the end of the investigation a CSF tap was performed by lowering the CSF pressure to a value of about $0 \mathrm{kPa}$, corresponding to the removal of 30-40 $\mathrm{ml}$ CSF. The CSF tap test comprised a comprehensive battery of tests administered the day before CSF hydrodynamic investigation (day 1) and at the same hour on day 2, around 3-4 hours after lowering the CSF pressure. ${ }^{5}$

POLYSOMNOGRAPHY

Each recording consisted of EEG, electrooculography (EOG), EMG, ECG, chest and abdominal movements (Resp-EZ, EPM Systems, Middlothian, VA, USA), oro-nasal airflow with a three way thermistor (Nihon, Khoden ZE-732A, Tokyo, Japan), and blood oxygen saturation with a finger transducer (Ohmeda Biox, 3740, Louisville, Colo, USA). All signals were printed out continuously on a 16 channel paper recorder (Mhon, Khoden, Tokyo, Japan), with a paper speed of $6 \mathrm{~mm} / \mathrm{s}$. The records were scored manually. Sleep was evaluated according to the manual of Rechtschaffen and Kales. ${ }^{12}$ The number of apnoeas and hypopneas per hour of sleep were estimated. Respiratory events were defined as apnoea when there was a reduction in the thermistor tracing to below $20 \%$ of baseline and hypopneas were events during which the thermistor tracing was reduced by more than $50 \%$ of baseline values. An event was considered obstructive when there was a persistence of respiratory effort, or after a reduction, an increase of respiratory effort, not having an effect on the thermistor tracing. Events lacking respiratory effort were considered central. Only events lasting at least 10 seconds and associated with an arousal (increase in submental muscle tone or increase in fast EEG activity lasting 2 seconds or more, at the end of the event) were included. Any patient with an apnoea/hypopnoea index (the number of respiratory events occurring per hour of sleep) $\geqslant 10$ (respiratory disturbance index $\geqslant 10$ ) was given the diagnosis of sleep disordered breathing. Whole night polysomnography, including respiratory indices, was recorded one week before the CSF tap test and during the first night after the test. Repeat polysomnographic evaluation was performed in all patients 3 to 9 months after shunting. Fourteen patients had a second follow up investigation 9-18 months after shunt operation.

STATISTICAL METHODS

Statistical analysis was carried out with JMP statistical software for the Macintosh computer. ${ }^{13}$ Spearman's $r$ was used to test for correlation between continuous variables. Differences between two means were assessed with Student's $t$ test for paired observations or the Wilcoxon signed rank test when appropriate. One way analysis of variance (ANOVA) was used for comparison of clinical nominal scale variables and continuous variables. Repeated measures ANOVA was used to determine the relevance of changes in polysomnographic characteristics over time and 95\% confidence intervals (95\% CIs) were calculated. Two sided $\mathrm{p}$ values $<0.05$ were considered to indicate significance.

\section{Results}

The demographic, clinical, CSF hydrodynamic, and neuroradiological characteristics are summarised in table 1 . The gait disturbance preceded the development of other symptoms in 16 patients. At admission three patients presented the fully developed triad of symptoms. Pcl was moderately raised and Gop was low compared with normal values. Fourteen patients were receiving various drugs not generally recognised to cause obstructive sleep apnoea, including antihypertensive drugs, diuretic drugs, antiplatelet aggregating agents, hypoglycaemic drugs, and corticosteroids. Two patients were taking antidepressant drugs and one patient took a low dose of analgesics containing codeine on an as needed basis. There was no significant change in medication during follow up. Dose regimes were essentially maintained unchanged over the follow up period (one patient stopped medication (an antidepressant)).

PREOPERATIVE POLYSOMNOGRAPHIC DATA AND CORRELATIONS WITH CLINICAL AND CSF HYDRODYNAMIC VARIABLES

Sixty five per cent $(65 \%)$ of the patients had respiratory disturbance index $>10$ (range 1252) and $47 \% \geqslant 20$. In four patients, the $\mathrm{SaO}_{2}$ monitoring device was not available and in one 
Table 2 Paired t test comparisons of the effect of removal of CSF on polysomnographic variables

\begin{tabular}{|c|c|c|c|c|}
\hline \multirow[b]{2}{*}{ Polysomnographia } & \multicolumn{2}{|c|}{ Before CSF removal $(n=15)$} & \multicolumn{2}{|c|}{ After CSF removal $(n=15)$} \\
\hline & Mean & $95 \% C I$ & Mean & $95 \% C I$ \\
\hline Total sleep time (min) & 331 & $278-384$ & 370 & $330-411$ \\
\hline Stage $1(\%)$ & 34 & $27-41$ & 32 & $23-40$ \\
\hline Stage $2(\%)$ & 45 & $39-52$ & 45 & $37-52$ \\
\hline REM stage (\%) & 10 & $5-14$ & 12 & $9-15$ \\
\hline Delta stage $(\%)$ & 11 & $6-16$ & 12 & $8-15$ \\
\hline Awakenings (n) & 30 & $24-35$ & 31 & $23-38$ \\
\hline Wakenings after onset of sleep ( $\min$ ) & 116 & $130-202$ & 142 & $96-187$ \\
\hline RDI & 18.1 & $11.0-25.1$ & $26.7^{\star}$ & $18.9-34.5$ \\
\hline
\end{tabular}

* $\mathrm{p}<0.05 v$ investigation before removal of CSF.

Table 3 Results of the polysomnographic investigations before and after surgery

\begin{tabular}{|c|c|c|c|c|c|c|}
\hline \multirow[b]{2}{*}{ Polysomnographia } & \multicolumn{2}{|c|}{ Before surgery $(n=17)$} & \multicolumn{2}{|c|}{ First follow up $(n=17)$} & \multicolumn{2}{|c|}{ Second follow up $(n=14)$} \\
\hline & Mean & $95 \% C I$ & Mean & $95 \% C I$ & Mean & $95 \% C I$ \\
\hline Total sleep time (min) & 323 & $275-371$ & 347 & $303-390$ & 359 & $308-409$ \\
\hline Stage $1(\%)$ & 36 & $28-44$ & $27^{\star}$ & $21-34$ & 31 & $21-40$ \\
\hline Stage $2(\%)$ & 44 & $38-51$ & 44 & $39-48$ & 50 & $44-56$ \\
\hline REM stage (\%) & 9 & $5-13$ & $13^{\star}$ & $9-16$ & 8.9 & $5.5-12.3$ \\
\hline Delta stage (\%) & 11 & $6-15$ & $16^{\star}$ & $11-21$ & 10 & $5-15$ \\
\hline Awakenings (n) & 28 & $23-34$ & 21 & $15-26$ & 25 & $16-34$ \\
\hline $\begin{array}{l}\text { Wakenings after onset of sleep } \\
\text { (min) }\end{array}$ & 164 & $130-198$ & $110^{\star}$ & $75-146$ & 127 & $95-160$ \\
\hline Respiratory disturbance index & 17.9 & $11.3-24.5$ & 21.5 & $13.1-27.1$ & 25.1 & $15.6-34.0$ \\
\hline
\end{tabular}

${ }^{\star} \mathrm{p}<0.05 v$ investigation before surgery.

patient the $\mathrm{SaO}_{2}$ reading was not reliable due to technical failure. There were no other deficiencies in the polysomnographic data. Twelve readings of $\mathrm{SaO}_{2}$ were thus available from the baseline polysomnographic studies and minimum oxygen saturation was strongly correlated to the MMSE $(r=0.82 ; \mathrm{p}<0.001)$. There were no further significant relations between polysomnographic, CSF hydrodynamic, and clinical variables at baseline.

There was no significant difference between CSF pressure in patients with respiratory disturbance index $<10$ and respiratory disturbance index $>10(\mathrm{p}=0.4)$ or respiratory disturbance index $\geqslant 20(p=0.5)$. Cheyne-Stokes respiration with regular "crescendo-decrescendo" fluctuations, was not identified in any of our patients, neither before nor after shunting.

\section{CSF TAP TEST}

Fifteen patients performed polysomnograhic recordings both before and after CSF tap. Gait function was significantly improved after the tap test $(p=0.002)$. After CSF removal respiratory disturbance index increased significantly $(\mathrm{p}=0.01$, table 2$)$. No other effects on polysomnographic variables were discernible from CSF tapping.

\section{POSTOPERATIVE CLINICAL AND}

POLYSOMNOGRAPHIC RESULTS

Cerebrospinal fluid hydrodynamic assessment of shunt function disclosed shunt failure in one patient postoperatively. The results of polysomnographic and clinical evaluations after shunt revision were included in the study. Seventy seven per cent of the patients had improved significantly in gait function and functional status at the first follow up after shunting (table 1). Cognitive performance evaluated by the MMSE was slightly improved in $29 \%$ of the patients. Neither respiratory disturbance index $(p=0.4)$ nor any other polysom- nograhic variable was predictive of postoperative outcome. In the 17 patients examined preoperatively and at their first follow up, REM and delta sleep increased significantly $(\mathrm{p}=0.01$; $\mathrm{p}=0.04$ respectively), whereas sleep stage 1 and time awake after sleep onset decreased after shunting (table 3 ). For the 14 patients investigated twice after shunting, statistical analysis was not able to show any modulating impact on respiratory disturbance index or sleep patterns over time.

\section{Discussion}

The present study suggests that sleep disordered breathing is very common in IAHS.

Polysomnographic evaluation in a series of 16 patients from various causes including 10 cases with IAHS has previously been reported. ${ }^{3}$ All 16 patients had some degree of sleep apnoea with apnoeic episodes ranging from 30 to 310 apnoeas a night but so far no other study has provided detailed information on this aspect. However, it must be borne in mind that, at least in an elderly background population, normal values have not been properly established although a few studies indicate a higher prevalence in elderly people. In the 50-60 year age group $14 \%$ of men and $6 \%$ of women had $>10$ apnoeas and hypopnoeas per hour of sleep. ${ }^{14}$ Sleep disordered breathing was found to be exceptionally prevalent in a randomly selected elderly sample aged 65 years and over in which an respiratory disturbance index $\geqslant 10$ was detected in $62 \%$ of the subjects, ${ }^{15}$ a prevalence close to that reported in the present study.

Although probably not more common than in the general population of elderly people, the occurrence of sleep disordered breathing may be a risk factor for further deterioration in a vulnerable setting superimposed on a preexistent CSF hydrodynamic disturbance and small vessel disease. Arterial hypertension is 
often recognised in patients with AHS as it is in our study and has been found to be highly significantly associated with IAHS. ${ }^{16}{ }^{17}$ It has been suggested that abnormalities in the subcortical white matter may play a pathogenetic part in the development of hydrocephalus. ${ }^{18}$ A low cerebral blood flow in the subcortical white matter has been a persistent finding in $\mathrm{AHS}^{18}$ and several studies have found more extensive white matter abnormalities pointing towards a state of ischaemia in the subcortical white matter. ${ }^{18} 20$ Recent studies have shown that haemodynamic changes can occur with possible changes in cerebral blood flow during obstructive sleep apnoeas with the potential for impairment of the cerebral circulation and impending cerebral ischemia in the postapnoeic phase. ${ }^{21}$ In addition, reduced cerebral perfusion accompanied by apnoea related hypoxaemia may further predispose to nocturnal cerebral ischaemia and contribute to the chronic progression of hydrocephalus.

Markedly increased intracranial pressure has been associated with the apnoeas of sleep disordered breathing ${ }^{21}$ and patients with severe sleep disordered breathing may have increased intracranial pressure during daytime that increases further during sleep. ${ }^{21}$ It is well known from overnight intracranial pressure recordings in patients with AHS that B-waves are a frequent manifestation and related both to different sleep stages, ${ }^{23}$ apnoea episodes, and rhythmic alterations of cerebral blood flow. ${ }^{24}$ We found no direct relation between respiratory disturbance index and intracranial pressure, but repetitive intracranial pressure variations are assumed to dispose to increased intracranial pressure and may partially explain the increase found in IAHS compared with normal controls.

It is not clear to what extent the presence of sleep disordered breathing may cause symptoms in elderly people. A respiratory disturbance index $\geqslant 10$ has been associated with some cognitive impairment. ${ }^{25}$ Measurements of $\mathrm{SaO}_{2}$ in patients with the adult hydrocephalus syndrome have hitherto not been reported. Our data are limited but minimum $\mathrm{SaO}_{2}$ and cognitive status were strongly correlated. Otherwise, we did not find any significant correlations between polysomnographic variables and clinical characteristics.

The characteristics of sleep profiles in patients with AHS have scarcely been reported and the results are conflicting. ${ }^{23}$ For young adults $^{26}$ our data show that delta sleep corresponding to sleep stages 3 and 4 is rare in most patients in addition to paucity of REM sleep and frequent awakenings during nighttime. This, however, may not be specific for IAHS, as sleep stages 3 and 4 are generally reduced in elderly people and it is well known that patients with dementia from various causes rarely show stage 3 or 4 sleep or REM sleep. Lumbar CSF drainage was not able to induce significant alterations in sleep structure, and after shunting there was no sustained improvement of sleep. However, the first polysomnographic investigation after shunting showed an improvement in REM and delta sleep compared with baseline values. This was clearly not related to any changes in respiratory disturbance index, but may be related to the clinical improvement most of the patients experienced after shunting.

Kuchiwaki et $a^{\beta}$ performed polysomnography on one occasion in six of their patients 4-15 months after shunt operations. Five patients was classified as idiopathic cases and in one patient AHS was secondary to head trauma. A marked reduction of apnoeas was noted in several patients. By contrast, our data show a persistence of sleep related obstructive respiratory events when repeated polysomnographic studies are performed up to 18 months after the shunt procedure. Our results imply that manipulation of CSF pressure and volume do not ameliorate sleep disordered breathing in patients with IAHS and, moreover, temporary CSF drainage seemed to trigger a change for the worse. After shunt operation most of our patients experienced some alleviation of hydrocephalus related symptoms in particular pertaining to gait function. By contrast cognitive status was unchanged or only improved to a minor degree, which may be related to persistent desaturations during sleep. This suggests that sleep disordered breathing has the potential of causing dysfunction rather than being a consequence of dysfunction and other complementary treatment modalities may be considered in selected cases. However, it cannot be ruled out that sleep disordered breathing could be an irreversible consequence of the hydrocephalus. A few of our patients tried treatment with continuous positive airway pressure after shunting but with equivocal results mainly due to difficulties in coping with the treatment. However, the presence of a shunt system may ameliorate the potential adverse effects of pressure waves generated by sleep related obstructive events.

We thank Karl-Oskar Hansson's Foundation and the Swedish Society of Neurologically Disabled (NHR).

1 Gislason T. Almqvist M, Eriksson C, et al. Prevalence of sleep apnoea syndrome among Swedish men-an epidemiological study. 7 Clin Epidemiol 1986;41:571-6.

2 McNamara ME, Millman RP, Epstein MH. The association of normal-pressure hydrocephalus with obstructive sleep apnoea. F Geriatr Psychiatry Neurol 1992;5:238-40.

3 Kuchiwaki H, Misu N, Hirai N, et al. Pre- and postoperative studies of sleep levels in patients with normal pressure hydrocephalus for an indication of operative treatment. In: Dietz H. Brock M, Klinger M, ed. Advances in neurosurgery. Berlin: Springer-Verlag, 1985;13:296-303s.

4 Malm J, Kristensen B, Fagerlund M, et al. CSF shunt hydrodynamics in patients with idiopathic adult hydrocephalus syndrome. $\mathcal{F}$ Neurol Neurosurg Psychiatry 1995;58: 715-23.

5 Malm J, Kristensen B, Karlsson T, et al. The predictive value of CSF hydrodynamic tests in patients with the idiopathic of CSF hydrodynamic tests in patients with the idiopathic
adult hydrocephalus syndrome. Arch Neurol 1995;52:783-9. 6 Folstein MF, Folstein SE, McHugh PR. Mini-mental state: 6 Folstein MF, Folstein SE, McHugh PR. Mini-mental state:
a practical method for grading the cognitive status of patients for clinicians. F Psychiatr Res 1976;12:189-98.

7 Mahoney FI, Bartel DW. Functional evaluation: Bartel index. Maryland State Medical fournal 1965;14:61.

8 Hachinski V, Iliff L, Zilhka E, et al. Cerebral blood flow in dementia. Arch Neurol 1975;32:632-7.

9 Hanson J, Levander B, Liliequist B. Size of the intracerebral ventricles as measured with computed tomography, encephalography, and echoventriculography. Acta Radiol Suppl ;346:98-106.

10 Ekstedt J. CSF hydrodynamic studies in man. 1. Method of constant pressure CSF infusion. If Neurol Neurosurg

11 Ekstedt J. CSF hydrodynamic studies in man. 2. Normal hydrodynamic variables related to CSF pressure and flow. $\mathcal{F}$ Neurol Neurosurg Psychiatry 1978;41:345-53. 
12 Rechschaffen A, Kales A. The manual of standardized terminology, techniques, and snoring system for sleep stage of human subjects. Washington, DC: Public

13 Sall J, Ng K, Hecht M. FMP. Cary: SAS Institute, 1991

14 Young T, Palta M, Dempsey J, et al. Occurrence of sleep disordered breathing among middle-aged adults. $N$ Engl $f$ Med 1993;328:1230-5.

15 Ancoli-Israel S, Kripke D, Klauber M, et al. Sleepdisordered breathing in community-dwelling elderly. Sleep 1991;14:486-95.

16 Krauss J, Regel J, Vach W, et al. Vascular risk factors and arteriosclerotic disease in idiopathic normal-pressure hydrocephalus of the elderly. Stroke 1996;27:24-9.

17 Graff-Radford NR, Godersky JC. Idiopathic normal pressure hydrocephalus and systemic hypertension. Neurology 1987;37:868-71.

18 Bradley W, Whittemore A, Watanabe A, et al. Association of deep white matter infarction with chronic communicating deep white matter infarction with chronic communicating
hydrocephalus. AfNR Am $\mathcal{F}$ Neuroradiol 1991;12:31-9.

19 Kristensen B, Malm J, Fagerlund M, et al. Regional cerebral blood flow, white matter abnormalities, and cerebrospinal fluid hydrodynamics in patients with idiopathic adult hydrocephalus syndrome. 7 Neurol Neurosurg Psychiatry 1996;60:282-8

20 Krauss JK, Regel JP, Vach W, et al. White matter lesions in patients with idiopathic normal pressure hydrocephalus and in an age-matched control group: a comparative study. Neurosurgery 1997;40:491-6.

21 Jennum P, Borgesen S. Intracranial pressure and obstructive sleep. Chest 1989;95:279-83.

22 Kuchiwaki H, Takada S, Ishiguri H, et al. Pressure wave with apnoea evaluated by sleep level in patient with ventricular dilation. Neurol Res 1988;10:105-11.

23 Krauss J, Droste D, Bohus M, et al. The relation of intracranial pressure B-waves to different sleep stages in patients with suspected normal pressure hydrocephalus. Acta Neurochir (Wien) 1995;136:195-203.

24 Newell DW, Aaslid R, Stoos R, et al. The relationship of blood flow velocity fluctuations to intracranial pressure B-waves. I Neurosurg 1992;76:415-21.

25 Fleury B. Sleep apnoea syndrome in the elderly. Sleep 1992; 15:S39-41.

26 Vitiello M, Prinz P. Sleep and sleep disorders in normal aging. In: Thorpy MJ, ed. Handbook of sleep disorders. New York: Marcel Dekker, 1990 